\title{
Technological Gap in Relation to Hybrid Rice Production Practices
}

\author{
Tripeshori Yambem $^{2} *$, Aheibam Tarajit Singh ${ }^{1}$ and Niranda Sharma Leihaothabam ${ }^{2}$ \\ ${ }^{1}$ KVK Utlou, Bishnupur, Manipur, India \\ ${ }^{2}$ Pandit Deen Dayal Upadhyay Institute of Agricultural Sciences, \\ Utlou, Bishnupur, Manipur, India \\ *Corresponding author
}

The study was conducted in nine villages in Patsoi sub division of Imphal- West district of Manipur. A total of 120 respondents were selected from the nine

\section{Keywords}

Technological gap, Hybrid rice,

Cultivation practices, Adoption

Article Info

Accepted:

05 February 2020

Available Online:

10 March 2020 villages through descriptive research design which form the sample size of the study. The data was elicited through personal interview method using structure interview schedule. Correlation analysis of technological gap of hybrid rice growers with independent variables was found that education, innovative proneness, economic motivation, mass-media exposure, contact with extension staff, source of information and knowledge about hybrid rice production technology were found to be negatively significant at 0.01 level of probability. After the analysis of the data the respondents were classified into three categories as low gap, medium gap and high gap category based, on their extent of technological gap on recommended hybrid rice cultivation practices. The overall technological gap with highest score was associated with medium category (56.67\%) followed by low category $(22.50 \%)$ and high category $(20.83 \%)$. This indicates that majority of the farmers where in partial gap due to lack of complete knowledge and information about the recommended practices in hybrid rice production technology.

\section{Introduction}

Agriculture is the back bone of India's food security and rural economic security which for centuries has shaped the culture of its human resources. More than 72.20 per cent of India's population living in village and majority of them are engaged in agricultural enterprises. Hybrid rice was first commercially cultivated in China in 1976 and its planting area had expanded to more than 13 million hectares by 1990 . Hybrid rice with a higher yield advantage over inbred varieties has helped China produce more than 300 million tonnes of paddy. Hybrid rice not only has a distinct yield advantage over inbred 
varieties but also is more responsive to fertilizer and can adapt to varying environments. Hybrid technology is one of the limited options which is the only proven technology currently available for stepping up rice production significantly. The hybrid rice on an average gives 10 to $15 \mathrm{q} / \mathrm{ha}$ additional yield over the conventional varieties (about $20 \%$ increase) which were recently introduced in the cultivation. Therefore, the introduction of hybrid and popularization of their production technology are feasible and readily adoptable to achieve the targeted production.

Manipur lies in the north eastern corner of Indian occupying an area of 22,327 sq. km of which $10 \%$ is in the valley and $90 \%$ in hills. Rice is also a staple food of Manipur and is grown in mainly mono-crop with rice accounting about $98 \%$ of food grains production. According to the data collected, the production of rice in 2017-18 is estimated as 431.02 thousand tonnes which exceed the production in 2016-17.

The area under rice crop is about 187.06 thousand hectares, with an average productivity of 2.30 million tonnes per hectares. Among the districts, Imphal-East, Imphal-West and Bishnupur district with a production of 104.45 thousand tones placed first, 90.56 thousand tones as second and 68.83 thousand tones as third in terms of rice productions in Manipur respectively. (Database on Agriculture Department: Manipur Area, production and yield for the year 2017-18).

According to the results of crop estimate of survey conducted by the Directorate of Economics \& Statistics the total area estimated under HYVs and IVs of paddy crop were $54.68 \%$ is $2015-2016$ as against $62.02 \%$ in 2014-15 whereas the proportion of area under other varieties of seed used was $45.32 \%$ in $2015-2016$ as against the $37.98 \%$ in 2014 15.The adoption of HYVs of paddy in the hill districts perhaps due to surface configuration of the hill areas continued to be negligible while that of IVs is quite encouraging. The proportions in the hill areas for the HYVs and IVs were 14.44 percent in 2015-16 as against 15.14 percent in 2014-2015. While in case of valley area is 100.00 percent in 2014-15 as against 93.01 percent in 2015-16 (Directorate of Economic \&Statistics, Govt. Manipur).

Driven by the necessity of higher production farmer of Manipur started the cultivation of hybrid rice since the beginning of the year 2001. Hybrid rice varieties like PA-6201, Loknath, Goralenath, Naina, Sahyadri, PAC801, PAC-807, CNPH-3, CORH-2, APRH-2, KRH-2, ARIZE-644, etc. were available in small quantities in the local market. They were grown and tested in the farmer's fields. Later, the Agriculture experts found PAC-801 and PAC- 807 would be more suitable for the state but, recently we have found that ARIZE6444 Gold in also one of the new variety which has been commonly used by the farmers. Hence, these three varieties were popularized by the State Agriculture Department through the centrally Sponsored scheme of ICDP (Integrated Cereal Development Programme), an on-going scheme in the state.

Agriculture technology is never completely accepted by the farmers is all respects, as such there always appears to be a gap between the recommended technology by the scientists and it's modified form at the farmer's level.

The technological gap is thus the major problem in the efforts of increasing agricultural production in the country. A need of the day is to reduce the technological gap between the agricultural technology recommended by the scientists and its acceptance by the farmers on their field. 


\section{Materials and Methods}

For the study descriptive research design was followed. Pilot study was also done to gain some primary information on the basis of which main project was planned and formulated. Imphal -West, district of Manipur, was selected purposively as the research scholar is from the said district. The district is divided into 4 sub-divisions: Lamphelpat, Wangoi, Lamshang and Patsoi, only one sub-division i.e., Patsoi was selected purposively because majority of the farmers are hybrid rice cultivators. Out of the total 30 villages in Patsoi sub-division, the farmers cultivating hybrid rice were selected for the study through complete survey method, making a sample size of 120 respondents in total i.e., Awangkhunou (13 respondents), Awangjiri (12 respondents), Kangmong (17 respondents), Khumbong (15 respondents), Moidangpok Khullen (18 respondents), Moidangpok Khunou (6 respondents), Salam (19 respondents), Luker (10respondents) and Ngairangbam (10 respondents).

\section{Methods of data collection}

For collection of data, structured interview schedule was prepared; the interview schedule was pre-tested so that it would be capable of eliciting appropriate response from the respondents. Data collection was done by the researcher herself accompanied by the knowledge or experience farmer/elderly person of the villages. Data was collected from farmers who cultivated hybrid rice of the respective villages.

\section{Statistical tools to be used for analysis of data}

The data collection through the schedule were coded, tabulated, analyzed and presented in tables in order to make findings more meaningful and easily understandable. The statistical tools and techniques used in this study are given below.

\section{Technological gap}

Technological gap index $=\frac{R-A}{A} \times 100$

$\mathrm{R}=$ Maximum possible adoption score that a respondent could be awarded in respect of a given component of the technology

$\mathrm{A}=$ Score obtained by a respondent by virtue of his adoption of a given component of the technology

\section{Frequency}

Frequency refers to the number of observation of individuals belonging to a group or class.

\section{Percentage}

For the percentage to be calculated the frequency of a particular cell was divided by the number of respondents in that category and multiplied by 100 .

\section{Arithmetic mean}

It is the sum of all values of observations divided by the total number of observation. It is denoted by $(\overline{\mathrm{X}})$ and can be presented symbolically as:

Arithmetic mean $(\bar{X})=\frac{\sum X}{N}$

Where,

$(\overline{\mathrm{X}})=$ Arithmetie mean.

$\sum \mathrm{X}=$ summation of item values.

$\mathrm{N}=$ number of items.

\section{Standard deviation}

Standard deviation is the square root of the arithmetic mean of the squares of all deviation; the deviation is being measured 
from the arithmetic mean of the distribution. It is commonly denoted by the symbol a (Sigma). The standard deviation of the data group in the form of a frequency distribution is computed by formula:

$S D=\sqrt{\frac{\sum\left(X_{i}-\bar{X}\right)^{2}}{n}}$

Where,

$\mathrm{Xi}=\mathrm{i}^{\text {th }}$ value of the independent variable,

$\mathrm{X}=$ Mean,

$\mathrm{n}=$ Total number of observation

\section{Correlation}

When an increase or decrease in one variate is accompanied by an increase or decrease in the other variate, the two are said to be correlated and the phenomenon is known as correlation coefficient (r) a measure of the relationship between two variables which are at the interval or ratio level of measurement and are linearly related. Pearson product-movement ' $r$ ' is computed by the formula:

$\mathrm{r}=\frac{\mathrm{N} \sum \mathrm{XY}-\left(\sum X\right)\left(\sum Y\right)}{\sqrt{\left[N \sum X^{2}-\left(\sum X\right)^{2}\right]\left[N \sum Y^{2}-\left(\sum Y\right)^{2}\right]}}$

Where,

$\mathrm{X}$ and $\mathrm{Y}=$ Original score in variables $\mathrm{X}$ and $\mathrm{Y}$ $\mathrm{N}=$ Number of paired scores

$\sum X Y=$ Each of $X$ multiplied by its corresponding $\mathrm{Y}$, then summed.

$\sum X=$ Sum of $X$ scores

$\sum X^{2}=$ Each $X$ squared, then summed

$\left(\sum X\right)^{2}=$ Sum of $X$ scores, squared

$\sum \mathrm{Y}=$ Sum of $\mathrm{Y}$ scores

$\sum Y^{2}=$ Each $Y$ squared, then summed

$\left(\sum Y\right)^{2}=$ Sum of $Y$ scores, squared

\section{Results and Discussion}

The findings of the study obtained from the data collection through investigation has been presented under the following heads
Extent of technological gap in relation to recommended hybrid rice production practices among the respondents

In the present study, an attempt has been made to investigate the technological gap in the adoption of selected recommended hybrid rice practices by the farmers. The practices selected for the study were recommended hybrid rice variety, seed treatment, seed rate, time of nursery raising, fertilizer use in nursery raising, plant protection in nursery, age of seedling, plant spacing, number of seedling per hill, transplanting time, quantity of fertilizers use, time of application (NPK), weeding and interculture, plant protection and water management. Table-1 shows the frequency and percentage of respondents having different levels i.e. low, medium and high gap of each of the practices adopted in the study.

From Table 1the data shows that all the respondents accorded per cent in 'no gap category' in the practices, because the hybrid variety was already adopted by the respondents. For seed treatment, 45.83 per cent of the respondents showed no gap, however majority of the respondents $(54.17 \%)$ found under the partial gap. For seed rate, 45.00 per cent of the respondents showed no gap in seed rate by adopting the recommended seed rate. However, majority of the respondents $(55.00 \%)$ found under partial gap. This might be due to reason that majority of the farmers normally ignored the adoption of the correct seed rate. For timely nursery raising, 48.33 per cent of the respondents showed no gap. However, majority of the respondents 51.67 per cent showed partial gap in timely nursery raising. The reason might be lack of sowing implements and nonavailability of seed in time. For fertilizer used in nursery, 17.50 per cent of the respondents showed no gap and 26.67 per cent of the respondents showed full gap in fertilizer used in nursery. However, majority of the 
respondents $(55.83 \%)$ were found under partial gap. For plant protection in nursery, 12.50 per cent of the respondents were found in full gap and 41.67 per cent were found in no gap on plant protection in nursery. However, majority of the respondent (45.83\%) were found under partial gap in these practices. Forage of seedling, 15.00 per cent of the respondents showed no gap and 38.33 per cent were found in full gap in age of seedling. However, majority of the respondent $(46.67 \%)$ were found under partial gap. For spacing, 24.17 per cent of the respondent showed full gap and 36.66 percent were found under no gap in transplanting spacing. However, majority of the respondents (39.17\%) were found under partial gap. The reason for using wider or lesser spacing by majority of the respondents might that they did not follow recommended spacing. For number of seeding per hill, 29.16 per cent of the respondent showed full gap and 32.50 per cent partial gap in number of seeding per hill. However, majority of the respondents $(38.34 \%)$ were found under no gap in number of seedlings per hills. For time of transplanting, 39.17 per cent of the respondents were found under no gap. However, majority of the respondents $(60.83 \%)$ were found under partial gap in time of transplanting. The reason for using no right time for transplanting for hybrid rice practices by majority of the respondents might be that they did not follow recommended time of transplanting. For nitrogenous fertilizer use, majority of the respondents $(52.50 \%)$ were found under partial gap in the use of recommended fertilizer dose followed by $(27.50 \%)$ of the respondents showed no gap and 20.00 per cent of the respondents showed full gap in the use of recommend fertilizer dose. It may be concluded that majority of the farmers had used nitrogenous fertilizers on their hybrid rice crop partially. This might be due to the fact they could visualize the pronounced effect of the fertilizer. For Phosphorus fertilizer use, majority of the respondents $(43.33 \%)$ was found under partial gap in the using of recommended phosphorus fertilizer. However $(37.5 \%)$ of the respondent showed no gap and $(19.17 \%)$ of the respondent showed full gap recommended phosphorus fertilizer. It may be conclude that majority of the farmers had used phosphate fertilizer on their hybrid rice crops partially. For potash fertilizer dose, majority of the respondents $(41.67 \%)$ showed full gap in the use of recommended fertilizer dose. However, 40.00 per cent of the respondents showed no gap and 18.33 per cent were under partial gap in using of potash fertilizers. It may be concluded that majority of the farmers had not used potash fertilizers on their hybrid rice crops fully. For weeding and inter-culture, majority of the respondents $(57.50 \%)$ were found under partial gap. However, 42.50 per cent of the respondent showed no gap in weeding and intercultural practice. It may, therefore, be concluded that most of the farmers had adoption intercultural practice partially. This is because most of them understood the injurious effect of weeds on standing rice crops. For plant protection measures, 26.67 percent of the respondents showed no gap. However, majority of the respondents $(45.00 \%)$ were in partial gap and 28.33 percent of the respondents were in full gap in using of recommended plant protection measures. The probable reason may be due to lack of knowledge, lack of technique guidance, high cost of plant protection chemical, non-availability of plant protection chemicals and lack of finance. For water management, majority $(65.00 \%)$ of the respondents were found under partial gap however 19.17 per cent of the respondents showed full and 15.83 per cent of the respondents showed no gap in using of recommended water level. The reasons for deviation from recommended level of water by majority of the respondents might be due 
to lack of knowledge of correct water level and another reason for this might be due to lack of irrigation facilities.

The data in Table 2 shows that majority of the respondents $(56.67 \%)$ belonged to medium category of technological gap followed by low level of technological gap $(22.50 \%)$. Only $(20.83 \%)$ of the respondents had high extent of technological gap on the basis of their overall technological gap. This indicates that majority of the farmers where in partial gap due to lack of complete knowledge and information about the recommended practices in hybrid rice production technology.

\section{Relationship between selected independent and dependent variables of the respondents}

Table3 deals with the nature of relationship between the selected dependent and independent variables. Correlation between the dependent variable-technological gap and the sixteenth independent variables were computed for the sample farmers. This helped in getting an idea about the relationship of the dependent variable with the independent variable. The ' $r$ ' values are shown in Table 3.

The data presented in Table 3 revealed that the age of the farmers showed positive and non-significant correlation with technological gap having ' $r$ ' value 0.052 . This indicated that the respondents did not vary in their technological gap on the basis of age, thereby implying that technological gap can be reduced successfully to all age group. Education was found to be negative and significant relationship with technological gap at 0.01 level of probability having ' $r$ ' value 0.345. It means education level of the hybrid rice growers increases, the technological gap decreases in adoption of hybrid rice technology. This might be due to the fact that higher education makes them more change and innovation proneness, more exposure to farm information leading to those knowledge and skill and more risk taking capacity. All these characteristics have enabled them to reduce the level of technological gap in the adoption of the hybrid rice cultivation. The finding was in line with that of Kadam et al., (2010). Family size showed negative and nonsignificant correlation with technological gap having ' $r$ ' value -0.069 . This indicated that the size of family was not correlated with technological gap of hybrid rice cultivation practices by them. It has shown that family size had failed to produce any significant effect on hybrid rice cultivation practices and so it was not more a determining factor for technological gap in the present study. It implies that hybrid rice cultivation practices can be successfully extended to all families irrespective of the size of families. The finding was in line with the research result of Singh (2004). Innovation proneness was found to be negative and significant with technological gap at 0.01 level of significant, having ' $r$ ' value -0.327 . It means innovation proneness of the hybrid rice growers increases, the technological gap decreases in adoption of hybrid rice technology. The finding was in line with the research result of Nikhade et al., (1997). Economic motivation was found to be negative and significant relationship with the technological gap at 0.01 level of significance having ' $r$ ' value -0.298 . It means economic motivation of the hybrid rice growers increases, the technological gap decreases in adoption of hybrid rice technology. The finding was in line with the research result of Patel and Padheria (2010). Risk orientation was found to be negative and significant relationship with the technological gap at 0.05 level of significant having ' $r$ ' value -0.223 . This indicated that higher the risk preference of respondents lesser was their technological gap of adoption process. The finding was in line with the research result of Kadam et al., (2010). Attitude towards pesticide use showed positive and significant 
correlation with technological gap at 0.05 level of have significant having ' $r$ ' value 0.220. This indicates that if the use attitude towards pesticides increases, the technological gap increases. Annual income of the farmers showed negative and nonsignificant correlation with the technological gap having ' $r$ ' value -0.064 . This indicated that the respondents were not influenced by their annual income. In other word, the farmers did not vary in their technological gap on the basis of annual income. Operational land holding of the farmers showed negative and non-significant relationship with their technological gap having ' $r$ ' value -0.151 . This suggests that their technological gap was not influenced by their size land holding size.
The finding was in line with the research result of Kumar et al., (2014). Cropping intensity showed negative and non-significant relationships with their technological gap having ' $r$ ' value -0.022 . This indicated that farmers did not vary in their technological gap on the basis of their cropping intensity. The finding was in line with the result of Ray et al., (1995). Social participation was found positive and non-significant correlation with technological gap having ' $r$ ' value 0.112 . It has shown that social participation had failed to produce any significant effect on hybrid rice cultivation practices and so it was not more a determining factor for technological gap.

Variables and their measurement techniques

\begin{tabular}{|c|c|}
\hline $\begin{array}{l}\text { Category of variables to be } \\
\text { undertaken }\end{array}$ & Measurement techniques \\
\hline \multicolumn{2}{|l|}{ A. Independent Variables } \\
\hline 1. Age & Chronological age of the respondents \\
\hline 2. Education & SES scale rural (Pareek and Trivedi, 1964) \\
\hline 3. Family size & SES scale rural (Pareek and Trivedi, 1964) \\
\hline 4. Innovative Proneness & Innovation proneness scale (Moulik, 1965) \\
\hline 5. Economic Motivation & Scale developed by Singh (1993) \\
\hline 6. Risk Orientation & Risk preference scale Supe (1969) \\
\hline 7. Attitude towards pesticides & Scale developed by Singh (2004) \\
\hline 8. Annual income & One mark was given to each 1000 rupees \\
\hline 9. Operational land holding & Scale developed by Basu (1993) \\
\hline 10. Cropping intensity & Structured schedule was developed \\
\hline 11. Social participation & Scale developed by Lokhande (1974) \\
\hline $\begin{array}{l}\text { 12. Participation in training } \\
\text { programme }\end{array}$ & Scale developed by Sagar (1983) \\
\hline 13. Mass media exposure & Schedule developed by Sagar (1983) \\
\hline 14. Contact with extension staff & Scale developed by Singh (1993) \\
\hline $\begin{array}{l}\text { 15. Sources of information } \\
\text { (Cosmopolite and locality) }\end{array}$ & Scale developed by Singh (1993) \\
\hline $\begin{array}{l}\text { 16. Knowledge about hybrid rice } \\
\text { production technology }\end{array}$ & Structure schedule was developed \\
\hline \multicolumn{2}{|l|}{ B. Dependent Variable } \\
\hline Technological Gap & Technological Gap Index \\
\hline
\end{tabular}


Table.1 Distribution of respondents on the basis of their technological gap in recommended hybrid rice practices

\begin{tabular}{|c|c|c|c|c|}
\hline \multirow{3}{*}{$\begin{array}{l}\text { Sl. } \\
\text { No. }\end{array}$} & \multirow{3}{*}{ Package of practices } & \multicolumn{3}{|c|}{ Extent of technological gap } \\
\hline & & Full gap & Partial gap & No gap \\
\hline & & $\begin{array}{c}\text { Frequency } \& \\
(\%)\end{array}$ & Frequency \& (\%) & $\begin{array}{c}\text { Frequency } \& \\
(\%)\end{array}$ \\
\hline 1. & Hybrid variety & & & $120(100.00)$ \\
\hline 2. & Seed treatment & & $65(54.17)$ & $55(45.83)$ \\
\hline 3. & Seed rate $(\mathrm{kg} / \mathrm{ha})$ & & $66(55.00)$ & $54(45.00)$ \\
\hline 4. & Time of nursery raising & & $62(51.67)$ & $58(48.33)$ \\
\hline 5. & Fertilizer use in nursery & $32(26.67)$ & $67(55.83)$ & $21(17.50)$ \\
\hline 6. & $\begin{array}{l}\text { Plant protection in } \\
\text { nursery }\end{array}$ & $15(12.50)$ & $55(45.83)$ & $50(41.67)$ \\
\hline 7. & Age of seedlings & $46(38.33)$ & $56(46.67)$ & $18(15.00)$ \\
\hline 8. & Spacing & $29(24.17)$ & 47 (39.17) & $44(36.66)$ \\
\hline 9. & Number of seedling/hill & $35(29.16)$ & $39(32.50)$ & $46(38.34)$ \\
\hline 10. & Time of transplanting & & $73(60.83)$ & 47 (39.17) \\
\hline 11. & Nitrogen fertilizer use & $24(20.00)$ & $63(52.50)$ & $33(27.50)$ \\
\hline 12. & Phosphatic fertilizer use & $23(19.17)$ & $52(43.33)$ & $45(37.50)$ \\
\hline 13. & Potash fertilizer use & $50(41.67)$ & $22(18.33)$ & $48(40.00)$ \\
\hline 14. & Weeding and inter-culture & & $69(57.50)$ & $51(42.50)$ \\
\hline 15. & Plant protection & $34(28.33)$ & $54(45.00)$ & $32(26.67)$ \\
\hline 16. & Water management & $23(19.17)$ & $78(65.00)$ & $19(15.83)$ \\
\hline
\end{tabular}

Table.2 Distribution of respondents on the basis of their overall technological gap

\begin{tabular}{|c|c|c|c|}
\hline Sl. No. & Category & Frequency & Percentage \\
\hline $\mathbf{1 .}$ & Low (Mean - S.D.) & 27 & 22.50 \\
\hline $\mathbf{2 .}$ & Medium (Mean \pm S.D.) & 68 & 56.67 \\
\hline $\mathbf{3 .}$ & High (Mean + S.D.) & 25 & 20.83 \\
\hline & Total & $\mathbf{1 2 0}$ & $\mathbf{1 0 0}$ \\
\hline
\end{tabular}


Table.3 Relationship between the selected independent and dependent variables of the respondents

\begin{tabular}{|c|l|c|}
\hline Sl. No. & \multicolumn{1}{|c|}{ Independent variables } & Co-efficient of correlation \\
\hline $\mathbf{1 .}$ & Age & $0.052^{\mathrm{NS}}$ \\
\hline $\mathbf{2 .}$ & Education & $-0.345^{* *}$ \\
\hline $\mathbf{3 .}$ & Family size & $-0.069^{\mathrm{NS}}$ \\
\hline $\mathbf{4 .}$ & Innovative proneness & $-0.327^{* *}$ \\
\hline $\mathbf{5 .}$ & Economic motivation & $-0.298^{* *}$ \\
\hline $\mathbf{6 .}$ & Risk orientation & $-0.223^{*}$ \\
\hline $\mathbf{7 .}$ & Attitude towards pesticides & $0.220^{*}$ \\
\hline $\mathbf{8 .}$ & Annual income & $-0.064^{\mathrm{NS}}$ \\
\hline $\mathbf{9 .}$ & Operational land holdings & $-0.151^{\mathrm{NS}}$ \\
\hline $\mathbf{1 0 .}$ & Cropping intensity & $-0.022^{\mathrm{NS}}$ \\
\hline $\mathbf{1 1 .}$ & Social participation & $0.112^{\mathrm{NS}}$ \\
\hline $\mathbf{1 2 .}$ & Participation in training programme & $-0.227^{*}$ \\
\hline $\mathbf{1 3}$ & Mass-media exposure & $-0.286^{* *}$ \\
\hline $\mathbf{1 4 .}$ & Contact with extension staff & $-0.398^{* *}$ \\
\hline $\mathbf{1 5}$ & Source of information & $-0.365^{* *}$ \\
\hline $\mathbf{1 6 .}$ & Knowledge about hybrid rice cultivation & $-0.948^{* *}$ \\
\hline
\end{tabular}

** Significant 0.01 level of probability

* Significant 0.05 level of probability NS Non Significant

The finding was in line with the research result of Kumar et al., (2014). There was negative significant correlation between participation in training and technological gap at 0.05 level of significant having ' $r$ ' value 0.227. It indicated that higher the participation in training, the lesser was the technological gap of the farmers. This might be due the fact that higher participation in training makes them more changed and more exposure to farmers' information leading to that knowledge and skill.

Exposure to mass-medias showed negative and significant relationship with the technological gap at 0.01 level of significant having ' $r$ ' value -0.286 . It shows that higher the respondents are exposed to mass media the lesser in the technological gap. Contact with extension staff was found to be negative and significant relationship with technological gap at 0.01 level of significant having ' $r$ ' value -0.398 in adoption of hybrid rice technology. It indicates that contact with extension staff of hybrid rice growers increases, the technological gap decreases in adoption of hybrid rice technology. The finding was in line with the research result of Patel and Padheria (2010). Sources of information were found to be negative and significant relationship with technological gap at 0.01 level of significant having ' $r$ ' value 0.365 in adoption of hybrid rice technology. It indicates that source of information of hybrid rice growers increases, the technological gap decreases in adoption of hybrid rice technology. Knowledge about hybrid rice cultivation was found to be negative and significant relationship with technological gap at 0.01 level of significant having ' $r$ ' value 0.948. It means that if their knowledge about hybrid rice cultivation increases, the technological gap decreases in adoption hybrid rice technology. 
On the basis of the study conducted, it can be concluded that the majority of the respondents $(56.67 \%)$ belonged to medium category of technological gap followed by low level of technological gap (22.50\%). Only (20.83\%) of the respondents had high extent of technological gap on the basis of their overall technological gap.

It may also be concluded that education, innovative proneness, economic motivation, mass-media exposure, contact with extension staff, source of information and knowledge about hybrid rice production technology were found to be negatively significant at 0.01 level of probability. This indicates that education, innovative proneness, economic motivation, mass-media exposure, contact with extension staff, source of information and knowledge about hybrid rice production technology of hybrid rice growers increases, the technological gap decreases in adoption of hybrid rice technology. Risk orientation and participation in training programme were found to negatively significant at 0.05 level of probability. This indicated that higher the risk orientation and participation in training programme of respondents, lesser was their technological gap of adoption process. Attitude towards pesticide use is positively significant at 0.05 level of probability with the technological gap of the respondents. This indicates that if the use attitude towards pesticides increases, the technological gap increases. Age and social participation of the farmers showed positive and non-significant correlation with technological gap while family size, annual income, operational land holdings and cropping intensity of the farmers showed negative and non-significant correlation with technological gap.So, it is suggested that the various government organization and institution should provide more programme exclusively for hybrid rice grower and effort should be made to minimize the technological gap in cultivation of their crop.

\section{Acknowledgement}

The authors are thankful to the Pandit Deen Dayal Upadhyay Institute of Agricultural Sciences. Utlou, Bishnupur, Manipur for providing all the facilities provided during this study.I also take the privilege to express my heartiest appreciation to all my family and friends forwho supported me financially and also for their unconditional love and care throughout my life and study.

\section{References}

Basu, D. (1993). Farmer's decision making process in purchasing pesticides. (Unpublished) Ph.D. Thesis, Department of Agriculture Extension, Bidhan Chandra KrishiViswaVidyalaya, West Bengal.

Kadam, S.D., Thombre, B.M. and Mande, J.V. (2010). The technological gap in sugarcane production technology. Journal of Maharashtra Agriculture University, 34 (3): 424-427.

Kumar, G.; Sailaja, V.; Satyagopal,P.V. and Prasad, S.V. (2014). Evaluation of profile characteristics of SRI cultivation farmers in relation to their extent of adoption of technologies. Current Biotica, 8(1) 36-41.

Lokhande, M.R. (1974). Socio- psychological factors associated with farm credit behaviour of Delhi farmers. (Unpublished) Ph. D. Thesis, Division of Agricultural Extension, Indian Agricultural Research Institute, New Delhi.

Moulik, T.K. (1965). A study of predictive values of some factors on adoption of nitrogenous fertilizers and the influence of sources of information on adoption behaviour. (Unpublished) Ph.D. Thesis. 
Indian Agricultural Research Institute, New Delhi.

Nikhade, D.M., Bhople, R.S. and Kale, N.M. (1997). Technological gap in cultivation of red gram, green gram and Bengal gram in Gulbarga district of Karnataka. Indian Journal of Extension Education 33 (1\&2): 72-75.

Pareek and Trivedi, G. (1964). Manual of socio-economic status scale (rural) Delhi, Manasayan.

Patel, Y.V. and Padheria, M.M. (2010).The extent of technological gap and its relationship with situational, personal, socio-economic psychological and communication characteristics of safflower growers. Indian Journal of Extension Education 14: 185-87.

Ray, G.L., Chatterjel, P. and Banerjee, S.N. (1995). Technological gap and Constraints in Agricultural technology transfer NayaPrakash, BidhanSarani, Calcutta.

Sagar, R.L. (1983). Study of agro-economic, socio psyschological and extension communication variables related with farmer productivity of major field crops in Haringhata Block. (Unpublished)
Ph.D. Thesis. Department of Agricultural Extension, Bidhan Chandra KrishiViswaVidyala, West Bengal

Singh, M.K. (2004). A study on technological gap in recommended package of practices of rice production technology by the medium, small and marginal farmers of Thoubal district, Manipur (Unpublished) Ph.D. Thesis, Department of Agricultural Extension, Bihar Chandra Krishi Viswa Vidyala, West Bengal.

Singh, Ng.N. (1993). The extent of adoption of improved rice practices by the scheduled caste farmers of Manipur. (Unpublished) Ph.D. Thesis Department of Social Sciences, Manipur University.

Singh, Sanjay. (2004). Attitude of the trained farmers towards vocational training imparted by Krishi Vigyan Kendras of Rewa Division. Ph.D. Thesis, A.P.S. University Rewa.

Supe, S.V. (1969). Factors related to differential degrees of rationality decision making among factors. (Unpublished) Ph.D. Thesis. Indian Agricultural Research Institute,

\section{How to cite this article:}

Tripeshori Yambem, Aheibam Tarajit Singh and Niranda Sharma Leihaothabam. 2020. Technological Gap in Relation to Hybrid Rice Production Practices. Int.J.Curr.Microbiol.App.Sci. 9(03): 860-870. doi: https://doi.org/10.20546/ijcmas.2020.903.101 